\title{
Hardiness and Burnout Syndrome: A Cross-Cultural Study among Portuguese and Brazilian Nurses
}

\author{
Mary Sandra Carlotto ${ }^{1}$ \\ Programa de Pós-Graduação em Psicologia da Pontifícia Universidade Católica do Rio \\ Grande do Sul, Porto Alegre, Rio Grande do Sul, Brasil \\ Cristina Queirós \\ Sofia Dias \\ Universidade do Porto, Porto, Portugal \\ Mariana Kaiseler \\ Carnegie Faculty, Leeds Metropolitan University, United Kingdon
}

\begin{abstract}
This cross-cultural study investigated and compared the influence of hardiness in burnout among Portuguese and Brazilian nurses, as measured by the Maslach Burnout Inventory- Human Service Survey (MBI-HSS) and the Personal Views Survey (PVS). The sample consisted of 630 nurses working in hospitals (394 Portuguese, 236 Brazilians). The statistical analysis using multiple linear regression showed that hardiness is a personality trait that explains burnout, presenting different predictive models for each sample. Results suggested that overall work characteristics and work settings of Portuguese and Brazilian nurses explained the differences found between the samples. Findings suggested that future applied interventions aiming to reduce burnout among Portuguese and Brazilian nurses, should contemplate different hardiness dimensions.
\end{abstract}

Keywords: Burnout, cross-cultural study, hardiness, nurses.

\section{Hardiness e Sindrome de Burnout: Um Estudo Transcultural entre Enfermeiros Portugueses e Brasileiros}

\section{Resumo}

Estudo transcultural que buscou explorar a influência do hardiness nas dimensões da Síndrome de Burnout em enfermeiros portugueses e brasileiros, avaliados através do Maslach Burnout Inventory-Human Services (MBI-HSS) e do Personal Views Survey (PVS). A amostra foi constituída por 630 enfermeiros (394 Portugueses, 236 Brasileiros) que exerciam as suas funções no contexto hospitalar. Os resultados, obtidos por meio de análise de Regressão Linear Múltipla, indicam que hardiness, enquanto traço de personalidade, explica de forma significativa a Síndrome de Burnout nos enfermeiros, revelando diferenças nos modelos preditivos de acordo com a nacionalidade. As evidências encontradas sugerem a importância das características do trabalho e do contexto laboral na explicação das diferenças encontradas em ambas as amostras. Os resultados sugerem que intervenções para reduzir o burnout dos enfermeiros portugueses e brasileiros devem contemplar as diferentes dimensões do hardiness.

Palavras-chave: Síndrome de burnout, personalidade resistente enfermeiros, estudo transcultural.

Endereço para correspondência: Programa de Pós-Graduação em Psicologia, Pontifícia Universidade Católica do Rio Grande do Sul, Av. Ipiranga, 6681, Partenon, Porto Alegre, RS, Brasil 90619-900. E-mail: mscarlotto@ gmail.com,cqueiros@fpce.up.pt, sofiarsdias@gmail.com e m.h.kaiseler@leedsmet.ac.uk 


\section{Hardiness y el Síndrome de Burnout: Un Estudio Transcultural con Enfermeros Portugueses y Brasileños}

\section{Resumen}

Se trata de un estudio transcultural que busca explorar la influencia del hardiness en las dimensiones del síndrome de burnout en enfermeras brasileñas y portuguesas, evaluados con el Maslach Burnout Inventory-Human Services (MBI-HSS) e do Personal Views Survey (PVS). La muestra fue constituida por 630 enfermeras (394 portugueses, 236 brasileños) que trabajavan en el contexto hospitalario. Los resultados obtenidos mediante análisis de regresión lineal múltiple indican que el hardiness, como un rasgo de la personalidad, explica significativamente el síndrome de burnout en enfermeras, mostrando diferencias significativas en los modelos de predicción de acuerdo con la nacionalidad. La evidencia destaca la importancia de las características del trabajo y el contexto de para explicar las diferencias encontradas en ambas muestras. Los resultados sugieren que las intervenciones para reducir el burnout en enfermeros portugueses y brasileños deben tener en cuenta las diferentes dimensiones de hardiness.

Palabras clave: Síndrome de Burnout, personalidad hardiness enfermeras, estudio transcultural.

The Syndrome of Burnout (SB) has received increased attention over the last years across nations. This fact is associated with a global change in socio economic factors, particularly moving from an economy based on industry to an economy based on services. Consequently, this change caused increased demands for professionals, experiencing more and more psychological pressure over time (Schaufeli, Leiter, \& Maslach, 2009).

Maslach and Jackson (1981) defined burnout symptoms as: (a) emotional exhaustion, in which professionals feel that they are no longer able to cope at a psychological level; (b) depersonalization (or cynicism), characterized as negative and cynical attitudes and feelings towards clients. The last dimension represents the interpersonal context dimension of burnout (c) reduced efficacy or personal accomplishment, understood as the professionals' tendency to evaluate oneself negatively, particularly their work with clients. It is related with feelings of incompetence and a lack of achievement at work.

Nursing has been considered the most stressful profession among health care workers (Pisanti, Van der Doef, Maes, Lazzari, \& Bertini, 2011). This is likely to be related with the different demands nurses face in the work context. Several work stressors experienced by nurses have been described in the literature. As an example, Gray-Toft and Anderson (1981) have identified stressors related with: physical environment (eg. workload); social environment stressors (eg. conflict with staff) and psychological environmental stressors (eg. death and dying, lack of staff support, uncertainty associated with treatment, and lack of preparation to deal with the emotional needs of patients and their families). Furthermore, as suggested by a report developed by Pricewaterhouse Coopers (2002) nurses enter the health care field with the believe that they will have the time, the resources, and continued support to meet the needs of their patients and give them a high level of quality care. However, as suggested by the same report. Hence, due to all these factors, nurses are likely to be more prone to burnout, which may negatively affect the quality of nursing care, increase turnover, absenteeism and reduced productivity (Raiger, 2005).

Added to this fact, individual characteristics have shown to also influence nurses' experience of stress in the work context (Saksvik-Lehouilliera et al., 2012). Additionally, culture appears to be an important concept influencing burnout levels among nurses (Turnipseed \& Turnipseed, 1997). However, little is known about the influence of personality factors predicting burnout 
among nurses across different cultures, especially between Portugal and Brazil. Since as suggested by Triandis and Suh (2002) there are both universal and culture-specific aspects of variation in personality. It would be interesting to further understand the differences in personality factors predicting burnout among nurses across cultures. Furthermore, as nursing is a profession that involves cultural care diversity (Leininger, 1978) it seems critical to further understand how personality factors across cultures predict nurses' burnout in order to design cultural sensitive interventions.

The model of Burnout proposed by Maslach, Schaufeli, and Leiter (2001) emphasizes the importance of work characteristics and context as predictors of burnout. However, it is lkely that personality traits also play an important role in the development of burnout. Although some evidence has emerged supporting this view, little is known about this particular relationship (Azeem, 2010; Ghorpade, Lackritz, \& Singh, 2007). In a meta-analysis conducted by Alarcon, Eschleman and Bowling (2009) examining the relationship between personality and burnout, it was found that self-esteem, self-efficacy, locus of control, emotional stability, extraversion, conscientiousness, agreeableness, positive affectivity, negative affectivity, optimism, proactive personality, and hardiness were associated with the three dimensions of the Maslach Burnout Inventory. Particularly, hardiness showed the stronger relationship with all the three dimensions of burnout compared with the other personality factors under study. As recommended by the authors, these findings highlight the need to further examine the relationship between hardiness and burnout.

Hardiness has been defined as a personality construct that reflects the extent to which a person is able to face stressors without experiencing ill effects, such as psychological or physical strains (Kobasa, 1979). Kobasa suggested that the concept is a resilience resource that can be applied in stressful situations and which is assumed to protect the person from stress. Hence, the construct has emerged as an important buffer in the relationship between stressors and illness (Maddi, 1999). Hardiness comprises a high sense of life and work commitment, perceptions of control, and high openness to change and challenge, as well as a more positive appraisal of stress. Thus, the dimensions of commitment, control and challenge define the construct of hardiness (Kobasa, Maddi, \& Puccetti, 1982). Commitment reflects a dedication to oneself and to one's work. Control is the extent to which an individual influences life events to ensure a particular outcome. Challenge refers to the extent to which individuals perceive challenges as opportunities. Risquez, Fernández and Sánchez-Meca (2011) suggested that hardiness influences the person's health through the type and intensity of the stressors experienced, and by restricting or assisting the use of specific coping strategies. This idea is also supported by research conducted by Beehr and Bowling (2005) examining hardiness as a moderator of stressor-strain relationships. More specifically, hardiness is expected to yield a negative relationship with burnout via effects on both the perceived and objective nature of the work environment (Alarcon et al., 2009).

In what concerns to the relationship between personality and burnout among nurses, some evidence has been found in the literature (e.g., Boyle Grap, Younger, \& Thornby, 1991; Ghorpade, Lackritz, \& Gangaram, 2011; Phillips, 2011; Risquez et al., 2011; SaksvikLehouilliera et al., 2012; Simoni \& Paterson, 1997). In particular, hardiness has shown to be a protector in the process of burnout among nurses (Garrosa, Rainho, Moreno-Jiménez, \& Monteiro, 2010).

Additionally, how individual differences influence the stress-strain outcomes seems to be an important topic of research in today's increasingly culturally mixed work environments (Györkös, Becker, Massoudi, Bruin, \& Rossier, 2012). In agreement with this idea, Smith, Fisher, and Sale (2001) suggested that recently the need for cross-cultural studies in Occupational Psychology (OP) research has become more and more evident. Despite this necessity, 
cross-cultural studies in OP are not very common, mostly due to methodological difficulties of cross-cultural research (Smith et al., 2001). Thus, the current study aimed to compare whether there was a different predictive model of hardiness in burnout for Portuguese and Brazilian nurses. Since this study is exploratory in nature, therefore no detailed hypothesis can be presented. However, contemplating nursing job characteristics variations across both countries, it is hypothesized that different dimensions of hardiness would predict burnout for Brazilian and Portuguese nurses. Findings from this original research study, will develop the theoretical knowledge in the area of cross-cultural research in OP, and will highly contribute to the applied field of nursing.

\section{Method}

\section{Participants}

This study was cross-sectional in nature (Grimes \& Shulz, 2002) and was conducted in Portuguese and Brazilian' hospitals. Data was collected across four large public general hospitals (1500 to 5000 employees) located in a major metropolitan city of both countries (PortoPortugal and Porto Alegre-Brazil). Participants included 630 nurses (394 Portuguese, 236 Brazilians). Portuguese sample' mean age was 34.3 $(S D=8.3)$ years old. Most were women $(77.2 \%)$, married (56.0\%), had children (61.0\%), and were in permanent positions (68.4\%). Participants worked in that hospital an average length of 10.2 years $(S D=7.9)$. Brazilian sample' mean age was $34(S D=8.2)$ years old. Participants were women $(81.4 \%)$, married $(61.9 \%)$, had children $(66.9 \%)$, and worked with the remainder in temporary positions of varying contract length (58.2\%). Participants had worked in a hospital an average length of 2.5 years $(S D=3.9)$.

\section{Instruments}

Sociodemographic and Occupational Questionnaire. The questionnaire pack gathered data regarding gender, age, marital status, children, sort of contract (temporary/long term), exclusi- vity (worked in other institution), time working in that institution.

Maslach Burnout Inventory - Human Services Survey (MBI-HSS; Maslach \& Jackson, 1981). The instrument was validated to Portuguese language by Carlotto and Câmara (2007). The MBI is a 22-item scale designed to measure three dimensions of BS: Emotional exhaustion (9 items), Depersonalization (5 items), and Personal accomplishment (8 items). Each item is answered on a five-point response scale ranging from 1 (never) to 5 (everyday). A separate score was calculated for each of the three subscales.

Personal Views Survey (PVS). Developed by Kobasa (1982), was used to assess hardiness, with a version adapted and translated to Portuguese language by Mallar and Capitão (2004). This instrument consists of 50 items measuring hardiness trait, composed by three dimensions: Commitment (16 items), Control (17 items) and Challenge (17 items). The frequency with which the subject experiences feelings relating to each scale is rated on a four point Likert scale ranging from 0 (not at all true) to 3 (completely true). A separate score was calculated for each of the three subscales.

\section{Procedure}

Hospitals management teams were contacted, to explain and present the aims of the study. Following research ethics approval from university and hospitals, permission was given to contact nurse's team leaders and schedule data collection procedures using anonymous questionnaires. The instruments used were part of a larger study on occupational health psychology in the workplaces. In the Brazilian sample, questionnaire pack was fulfilled in the presence of a researcher. In the Portuguese sample, questionnaires were handed in to participants and returned by post to the researcher. Fulfillment of the questionnaire took approximately 20 minutes to complete. Data collection for both countries was collected over the year of 2010. All participants were informed that their answers would be treated anonymously and confidential- 
ly. Written informed consent was obtained from participants. No financial or material incentives were offered to participants.

The statistical program PASW version 18 (SPSS/PASW, Chicago, IL) was used to conduct data analysis. After screening for outliers and normality, Cronbach alphas were obtained for all study variables. Descriptive statistics were used to calculate frequencies, mean scores, and standard deviations. The strength and direction of relationships among variables were determined using the parametric Pearson's correlation coefficient measure. Prior to performing the regression analysis, the data were checked for multicollinearity, normality, linearity, homoscedasticity, independence of residuals and outliers. No major violations of the assumptions of the regression analysis were found. Multiple linear regression analyses (Stepwise Method) were performed to investigate the relationship between burnout and hardiness for the Portuguese and Brazilian samples. The three PVS subscales were used as the independent variables and the three MBI subscales were used as the dependent variables. Hence, sex, age and time of service were controlled and three separate hierarchical regression analyses were performed. The selec- tion of the predictor variables was performed with the level of significance $p<.05$. In order to provide a more objective measure of the size of the observed differences between the two samples (Portugal and Brazil), effect sizes for the regression analyses were also calculated using Effect size $R^{2}$ where values of $<.01$ indicate small, $<.059$ medium and $>.138$ large effect sizes (Field, 2009).

In regression analysis, to compare the power of the obtained significant effects, standardized regression coefficients - which can be considered as effect sizes in terms of standard deviation units - were calculated for each final model.

\section{Results}

The results of internal consistencies (Cronbach's $\alpha$ ) and correlations between the variables of the MBI and PVS are showed among Portuguese (Table 1) and Brazilian nurses (Table 2). The correlation matrix showed that there were significant correlations between the independent and the dependent variables for both cultures. The personality variables had a positive, significant correlation with personal accomplishment and a negative, significant correlation with emotional exhaustion and depersonalization.

Table 1

Internal Consistencies (Cronbach's $\alpha$ ) and Correlations of the Dimensions of the MBI and PVS $(n=394)$ - Portuguese Nurses

\begin{tabular}{lcccccccc}
\hline \multicolumn{1}{c}{ Variable } & $M$ & $S D$ & $(1)$ & $(2)$ & $(3)$ & $(4)$ & $(5)$ & $(6)$ \\
\hline 1. Emotional Exhaustion & 2.68 & .77 & $(.89)$ & & & & & \\
2. Depersonalization & 1.86 & .69 & $.427^{* *}$ & $(.73)$ & & & & \\
3. Personal Accomplishment & 3.79 & .52 & $-.213^{* *}$ & $-.238^{* *}$ & $(.74)$ & & & \\
4. Commitment & 2.01 & .31 & $-.455^{* *}$ & $-.372^{* *}$ & $.317^{* *}$ & $(.76)$ & & \\
5. Control & 2.01 & .27 & $-.382^{* *}$ & $-.356^{* *}$ & $.309^{* *}$ & $.750^{* *}$ & $(.73)$ & \\
6. Challenge & 1.63 & .25 & $-.390^{* *}$ & $-.298^{* *}$ & $.141^{* *}$ & $.523^{* *}$ & $.504^{* *}$ & $(.66)$ \\
\hline
\end{tabular}

Note. ${ }^{* *} p<.01$; Cronbach's $\alpha$ of the different scales on diagonal. 
Table 2

Internal Consistencies (Cronbach's $\alpha$ ) and Correlations of the Dimensions of the MBI and PVS $(n=236)$ - Brazilian Nurses

\begin{tabular}{|c|c|c|c|c|c|c|c|c|}
\hline Variable & $M$ & $S D$ & (1) & (2) & (3) & (4) & $(5)$ & $(6)$ \\
\hline 1. Emotional Exhaustion & 2.23 & .71 & $(.87)$ & & & & & \\
\hline 2. Depersonalization & 1.83 & .66 & $.529 * *$ & $(.67)$ & & & & \\
\hline 3. Personal Accomplishment & 3.85 & .63 & $-.282 * *$ & $-.287 * *$ & $(.78)$ & & & \\
\hline 4. Commitment & 2.23 & .41 & $-.366 * *$ & $-.375 * *$ & $.471 * *$ & $(.76)$ & & \\
\hline 5. Control & 2.11 & .36 & $-.375 * *$ & $-.403 * *$ & $.455^{* *}$ & $.757 * *$ & $(.70)$ & \\
\hline 6. Challenge & 1.60 & .35 & $-.301 * *$ & $-.297 * *$ & $.195 * *$ & $.621 * *$ & $.579 * *$ & $(.68)$ \\
\hline
\end{tabular}

Note. ${ }^{* *} p<.01$; Cronbach's $\alpha$ of the different scales on diagonal.

Results of the hierarchical regression analyses are showed in Table 3 for Portuguese nurses and in Table 4 for Brazilian nurses. For the Portuguese nurses, results obtained for the dimension of Emotional Exhaustion suggested that the predictor model is characterized by the dimensions of Commitment and Challenge. This regression model explained $27 \%$ of the variance of Emotional Exhaustion, revealing the highest explanatory power compared with other dimensions of burnout. In what concerns to Depersonalization for the Portuguese nurses, the final model was explained by the dimensions of Commitment, Challenge and Control by almost $22.3 \%$ of the variance. Commitment and Control together accounted for almost 13.8\% of the variance in Personal Accomplishment. In what relates to the results for the Portuguese nurses, it was found that Commitment $(\beta=$ $-.372)$ and Challenge $(\beta=-.193)$ had a negative relation with Emotional Exhaustion, suggesting that high levels of Commitment and Challenge predicted lower levels of Emotional Exhaustion at work. Depersonalization seemed to decrease, as Commitment ( $\beta=-.189)$, Challenge ( $\beta=$ -.127), and Control ( $\beta=-.156)$ increased. Personal Accomplishment was positively related with Commitment $(\beta=.219)$ and Control $(\beta=.146)$. Among Portuguese nurses, Commitment seemed to be the dimension of hardiness that best predicted variability in burnout.

When analyzing the Brazilian nurses, Emotional Exhaustion was predicted by Commit- ment and Control with almost $25 \%$ of variance. Control accounted for $24.3 \%$ of the variance in Depersonalization. Personal Accomplishment was predicted by Commitment and Control with almost $25.6 \%$ of variance. The results revealed a negative relation between Emotional Exhaustion, Commitment $(\beta=-.250)$ and Control $(\beta=$ -.206), suggesting that high levels of Commitment and Control tend to decrease Emotional Exhaustion at work. Depersonalization was negatively predicted by Control $(\beta=-.256)$. Personal Accomplishment was predicted by Commitment and Control. These results revealed a positive relation between the burnout dimension Personal Accomplishment, and the hardiness dimensions Commitment $(\beta=.298)$, and Control $(\beta=.223)$. It seems that for the Brazilian nurses, Control was the dimension of hardiness that best predicted variability in burnout. Overall, results found are between the medium $\left(R^{2}=.120\right)$ and large effect sizes $\left(R^{2}=.256\right)$ recommended by Field (2009). 
Table 3

Regression Analysis Summary for the Portuguese Nurses

\begin{tabular}{lccccccc}
\hline \multicolumn{1}{c}{ Variables } & $R^{2}$ & $R^{2 \text { Adjusted }}$ & $B$ & SE & $\beta$ & $t$ & $p$ \\
\hline Variable: Emotional exhaustion & & & & & & & \\
Commitment & .243 & .235 & -.928 & .128 & -.372 & -7.265 & $.000^{* *}$ \\
Challenge & .270 & .261 & -.597 & .158 & -.193 & -3.777 & $.000^{* *}$ \\
Model F & & & & $28.633 * *$ & & & \\
Variable: Depersonalization & & & & & & & \\
Commitment & .197 & .189 & -.421 & .158 & -.189 & -2.658 & $.008^{* *}$ \\
Challenge & .213 & .203 & -.354 & .149 & -.127 & -2.375 & $.018^{*}$ \\
Control & .223 & .211 & -.403 & .180 & -.156 & -2.243 & $.025^{*}$ \\
Model F & & & & $18.520^{* *}$ & & & \\
Variable: Personal accomplishment & & & & & & & \\
Commitment & .120 & .111 & .370 & .122 & .219 & 3.018 & $.003^{*}$ \\
Control & .130 & .118 & .286 & .141 & .146 & 2.024 & $.044^{*}$ \\
Model F & & & & $11.534^{* *}$ & & & \\
\hline
\end{tabular}

$* * p<.01 ; * p<.05$

Table 4

Regression Analysis Summary for the Brazilian Nurses

\begin{tabular}{lccccccc}
\hline \multicolumn{1}{c}{ Variables } & $R^{2}$ & $R^{2}$ Adjusted & $B$ & SE & $\beta$ & $t$ & $p$ \\
\hline Variable: Emotional exhaustion & & & & & & & \\
Commitment & .232 & .218 & -.435 & .163 & -.250 & -2.664 & $.008^{*}$ \\
Control & .250 & .232 & -.401 & .183 & -.206 & -2.196 & $.029^{*}$ \\
Model F & & & & $13.808^{* *}$ & & & \\
Variable: Depersonalization & & & & & & & \\
Control & .243 & .228 & -.455 & .166 & -.256 & -2.736 & $.007^{* *}$ \\
Model F & & & & $16.598^{* *}$ & & & \\
Variable: Personal accomplishment & & & & & & & \\
Commitment & .235 & .221 & .457 & .144 & .298 & 3.182 & $.002^{* *}$ \\
Control & .256 & .238 & .383 & .161 & .223 & 2.384 & $.018^{*}$ \\
Model F & & & & $14.221^{* *}$ & & & \\
\hline
\end{tabular}

${ }^{* *} p<.01 ; * p<.05$ 


\section{Discussion}

The main aim of this paper was to explore whether there was a different predictive model of hardiness in burnout for Portuguese and Brazilian nurses. Results partially support our hypothesis that the predictive model of hardiness in burnout among nurses in these two countries is mainly different, except for personal accomplishment. Additionally, although the values were relatively low, our findings showed that all the dimensions of hardiness were related with burnout for both the Portuguese and Brazilian nurses. Hence, in agreement with previous research (e.g., Azeem, 2010; Ebling \& Carlotto, 2012; Garrosa et al., 2010), our results suggest that hardiness, as personality trait, is likely to explain only part of the experience of burnout for Portuguese and Brazilian nurses.

Results suggest that there are differences between nurses in Brazil and Portugal in what concerns to variables explaining Emotional Exhaustion and Depersonalization. Particularly, for Portuguese nurses, it seems that Commitment was the personality trait that best explained variability in burnout. On the other hand, for Brazilian nurses, Control seemed to be the most important variable explaining burnout. We believe that these findings can be partially explained by the differences in the type and context of work nurses face in each one of the countries. Furthermore, these results are likely to be related with the overall work culture of each country. In Portugal, nurses job, involves spending most of their time involved in direct patient care, independently of their health status. Thus, the relationship developed between the nurse and the patient has almost a therapeutic effect. Until recently, nurses in Portugal were expected to establish a strong nurse-patient relationship, besides the technical skills required in caring. Nurses were also required to show empathy and kindness for the patient health status and support patient empowerment (Amendoeira, 2006). When analyzing the Portuguese nurses in our study, the best predictors of Emotional Exhaustion for these participants were Commitment and Challenge. It is believed that these findings may be explained by the professional emphasis of nurses' job in Portugal, since it is more based on nurse-patient assistance and care (Antunes, 2007). Additionally, these findings also support previous theory in the area of assistance care jobs (Edelwich \& Brodsky, 1980), suggesting that people who work in health care professions are strongly motivated by the will to help others. Furthermore, when analysing the Brazilian and Portuguese nurse's demographic characteristics, it is clear that Portuguese nurses spend more time working in the same institution, compared with Brazilian nurses. Thus, they suffer less changes in their work environment. This fact is extremely important in assistant care jobs, since professionals have an opportunity to develop their experience of learning and personal growth in that institution (Leipold, Schacke, \& Zank, 2008). On the other hand, Brazilian nurses job implies different tasks on a daily basis, compared with the Portuguese ones. These include providing care and support to patients, and conduct administrative work. In this way, in order to perform these tasks Brazilian nurses are required not only to have stronger technical knowledge in the area, but also strong management skills (e.g., decision making, leadership, good communication skills), and administrative skills (e.g., organize paperwork related with equipment and reports to supervisors; Peres \& Ciampone, 2006). Additionally, nurses in Brazil face innumerous changes in their work environment. Some of these include organization shifting their mission from service to enterprise due to serious financial problems. In agreement with this point, Guevara and Mendias (2002) suggested that Latin American countries have experienced increased acuity in hospitalized patients and increased service demand due to coverage expansion (because of universal coverage in Latin American countries), along with greater emphasis on cost control. Additionally, the authors added that payment systems for patients and providers have changed, with emphasis on reimbursement, stricter reimbursement requirements, and strategies such as managed care. Finally, administrative changes for Brazilian nurses include the use of organizational matrices in which nurses appear 
to report to more than one supervisor, they have responsibilities for more than one area, there is a redistribution of nursing resources, and a focus on interdisciplinary teams. Thus, it is clear that the profession of nurse in Brazil is related with different tasks, and more challenges compared with the profession of nurse in Portugal. Hence, our findings tend to somehow highlight these differences, since that Brazilian nurses seem to use more Control, possibly for facing the different tasks and changes at work. This result may be explained by Brazilian nurses possibly believing that their actions will influence work events, anticipating future threats, and decreasing in this way Emotional Exhaustion. Additionally, the second strongest predictor of burnout among Brazilian nurses was Commitment, suggesting that although this individual characteristic is present in the sample, it is likely to come after the management and administrative tasks.

Finally, for the Portuguese nurses the three dimensions of hardiness are likely to be protective factors against Depersonalization, whereas for the Brazilian nurses only two dimensions of hardiness (commitment and control) predicted burnout. It is believed that these findings suggest that Portuguese nurses may be better prepared to face the process of distancing from patients, when compared with Brazilian nurses.

It is important to highlight that findings were similar for the burnout dimension Personal Accomplishment across both samples. In other words, Commitment and Control predicted Personal Accomplishment among Portuguese and Brazilian nurses. This result can be explained by a historical and universal meaning, related with nursing job. In support of this idea, White (2002) suggested that nursing vocation is to be dedicated and committed to assisting another one who is disadvantaged, seeking public recognition of their work. The variance explained by this model was larger among Brazilian nurses (25.6\%) compared with Portuguese nurses (13\%).

Functional, cultural, economic and contextual factors of organizations do also play an important role in influencing professional's behavior (Hofstede, 1991; Raiger, 2005; Silva \& Gomes, 2009; Vanheule, Rosseel, \& Vlerick,
2007). Hence, it is believed that these factors may also contribute to the explanation of similarities and differences found in the predictive models of burnout among Portuguese and Brazilian nurses in the current study. In agreement with this idea, Vanheule et al. (2007) suggested that burnout differences across samples can be influenced by differences in job content, work circumstances, and professional goals in the respective sectors.

Our results, support the idea that personality traits are important predictors of burnout (Azeem, 2010; Ghorpade et al., 2011; Schaufeli \& Enzmann, 1998; Sheard \& Golby, 2007). Additionally, the percentage of explanation of the variation found in burnout in our study (between $12 \%$ and $27 \%$ ) was superior to that found previously in a study by Ghorpade et al. (2011) in the occupational setting. Particularly, the authors found that personality provides an additional $6.9 \%$ of explanation of the variation of emotional exhaustion; an additional $11.7 \%$ explanation of the variation in depersonalization; and an additional $13.8 \%$ of the variation in personal accomplishments. As suggested by Azeem (2010), the minimum variance of $10 \%$ was considered significant and meaningful. These findings support previous literature in the area, suggesting that burnout is an interaction between variables in the work context and personality factors $(\mathrm{Ca}-$ no-García，Padilla-Muñoz，\& Carrasco-Ortiz, 2005). In sum, some individual characteristics such as hardiness, may work as protectors against occupational stress and burnout among Portuguese and Brazilian nurses. A major strength of this study was the use of a strong theoretical basis, as well as reliable and accurate instruments for data collection purposes. Additionally, the effect size found, fit the values recommended by Cohen (1988).

The encouraging results of this study should be considered in light of several limitations. Firstly, as a cross-sectional study, it precludes evaluation of temporality and causality of the observed relationships. Further research is required using longitudinal or experimental designs. Secondly, although sample size of the samples support the statistical analyses, results cannot be 
generalized, due to samples being collected in public hospitals in a specific geographic region of Brazil and Portugal.

To our knowledge, this study is the first to compare the relationship between hardiness and burnout among Brazilian and Portuguese nurses. When aiming to achieve a competent system of care, research should conduct cross-culturally studies, aiming to understand similarities and differences between the cultures, and valuing diversity (Cross Bazron, Dennis, \& Isaacs, 1989).

Careful should be drawn when designing immediate definitive practical interventions based on the results of this study. However, it is important to highlight that applied practitioners in the area, should aim to increase hardiness training among Brazilian and Portuguese nurses when aiming to prevent burnout. As suggested by Maddi (2008) this personality construct is actively developed through a dynamic process. In other words, although life is stressful because it is always changing, people can turn stressful life events into opportunities for growth. Despite limitations, our results are consistent with previous trends in studies conducted in different clinical, cultural and social contexts around the world, adding considerable credibility to the findings. It is believed that this sort of cross-cultural research among nurses develops the theoretical knowledge in the area of cultural diversity among this profession, and provides an important basis for the design of applied interventions.

\section{References}

Alarcon, G., Eschleman, K. J.,\&Bowling, N.A.(2009). Relationships between personality variables and burnout: A meta-analysis. Work \& Stress, 23(3), 244-263. doi:10.1080/02678370903282600

Amendoeira, J. (2006). Uma Biografia partilhada da Enfermagem. A segunda metade do Século XX [A Biography of Nursing shared. The second half of the XX Century]. Coimbra, Portugal: Formasau.

Antunes, L. (2007). Processos e trajectórias de socialização em enfermagem - Uma reflexão sociológica sobre a construção de identidades sociais e profissionais dos estudantes [Processes and pathways of socialization in nursing - A sociological reflection about the development of social and professional identities among students]. In A. Rodrigues et al. (Eds.), Processos de formação na e para a prática de cuidados [Training processes in and for practice care] (pp. 93123). Loures, Portugal: Lusociência.

Azeem, S. M. (2010). Personality hardiness, job involvement and job burnout among teachers. International Journal of Vocational and Technical Education, 2(3), 36-40.

Beehr, T. A., \& Bowling, N. A. (2005). Hardy personality, stress, and health. In C. L. Cooper (Ed.), Handbook of Stress Medicine and Health ( $2^{\text {nd }}$ ed., pp. 194-21). New York: CRC Press.

Boyle, A., Grap, M. J., Younger, J., \& Thornby, D. (1991). Personality hardiness, ways of coping, social support and burnout in critical care nurses. Journal of Advanced Nursing, 16(7), 850857. doi:10.1111/j.1365-2648.1991.tb01767.x

Cano-García, F. J., Padilla-Muñoz, E. P., \& Carrasco-Ortiz, M. A. (2005). Personality and contextual variables in teacher burnout. Personality and Individual Differences, 38(4), 929-940. doi:10.1016/j.paid.2004.06.018

Carlotto, M. S., \& Câmara, G. S. (2007). Propriedades psicométricas do Maslach Burnout Inventory (MBI) em uma amostra multifuncional [Psychometric properties of the Maslach Burnout Inventory (MBI) among a multifunction sample]. Estudos de Psicologia (Campinas), 24(3), 325332. doi:10.1590/S0103-166X2007000300004

Cohen, J. (1988). Statistical power analysis for the behavioral sciences ( $2^{\text {nd }}$ ed.). Mahwah, NJ: Lawrence Erlbaum.

Cross, T., Bazron, B., Dennis, K., \& Isaacs, M. (1989). Towards a culturally competent system of care. Washington, DC: Child Development Center, Georgetown University.

Edelwich, J., \& Brodsky, A. (1980). Burnout: Stages of disilusionment in the helping profession. New York: Human Sciences Press.

Ebling, M., \& Carlotto, M. S. (2012). Burnout syndrome and associated factors among health professionals of a public hospital. Trends in Psychiatry and Psychotherapy 34, 23-30. doi.org/10.1 590\%2FS2237-60892012000200008

Field, A. (2009). Discovering Statistics with SPSS ( $\left.2^{\text {nd }} e d.\right)$. London: Sage. 
Garrosa, E., Rainho, C., Moreno-Jiménez, B., \& Monteiro, J. M. (2010). The relationship between job stressors, hardy personality, coping resources and burnout in a sample of nurses: A correlational study at two time points. International Journal of Nursing Studies, 47, 205-215. doi:10.1016/j.ijnurstu.2009.05.014

Guevara, E. B., \& Mendias, E. P. (2002). A comparative analysis of the changes in nursing practice related to health sector reform in five countries of the Americas. Pan American Journal of Public Health, 12(5), 347-353. doi:10.1590/S102049892002001100009

Ghorpade, J., Lackritz, J., \& Gangaram, S. (2011). Personality as a moderator of the relationship between role conflict, role ambiguity, and burnout. Journal of Applied Social Psychology, 41(6), 1275-1298. doi:10.1111/j.15591816.2011.00763.x

Ghorpade, J., Lackritz, J., \& Singh, G. (2007). Burnout and personality: Evidence from academia. Journal of Career Assessment, 15, 240-256. doi:10.1177/1069072706298156

Grimes, D. A., \& Shulz, K. F. (2002). An overview of clinical research: The lay of the land. The Lancet, 359, 57-61. doi: 10.1016/S01406736(02)07283-5

Gray-Toft, P., \& Anderson, J. G. (1981). Stress among hospital nursing staff: It's causes and effects. Social Science Medicine. 15A, 639-647. doi:10.1016/0271-7123(81)90087-0

Györkös, C., Becker, J., Massoudi, K., Gideon, P. de B., \& Rossier, J. (2012). The impact of personality and culture on the job demands control model of job stress Swiss. Journal of Psychology, 71(1), 21-28. doi:10.1024/1421-0185/a000065

Hofstede, G. (1991). Culture and Organizations: Software of the mind. New York: McGraw-Hill.

Kobasa, S. C. (1979). Stressful life events, personality and health: An inquiry into hardiness. Journal of Personality and Social Psychology, 37(1), 1-11. doi:10.1037/0022-3514.37.1.1

Kobasa, S. C. (1982). The hardy personality: Toward a social psychology of stress and health. In G. Sanders \& J. Suls (Eds.), Social psychology of health and illness (pp. 3-32). Hillsdale, NJ: Erlbaum.

Kobasa, S. C., Maddi, S. R., \& Puccetti, M. C. (1982). Personality and exercise as buffers in the stress- illness relationship. Journal Behavioral Medicine, 5, 391-404. doi:10.1007/BF00845369

Leipold, B., Schacke, C., \& Zank, S. (2008). Personal growth and cognitive complexity in caregivers of patients with dementia. European Journal of Ageing, 5, 203-214. doi:10.1007/s10433-0080090-8

Leininger, M. (1978). Transcultural nursing: Theories, concepts and practices. New York: John Wiley \& Sons.

Maddi, S. R. (1999). The personality construct of hardiness: Effects on experiencing, coping, and strain. Consulting Psychology Journal: Practice and Research, 51(2), 83-94. doi:10.1037/10614087.51.2.83

Maddi, S. R. (2008). The courage and strategies of hardiness as helpful in growing despite major, disruptive stresses. American Psychologist, 63, 563-564. doi:10.1037/0003-066X.63.6.563

Mallar, S. C., \& Capitão, C. G. (2004). Burnout e hardiness: Um estudo de evidência de validade [Burnout and hardiness: A study of the evidence of validity]. Psico-USF, 9(1), 19-29. doi:10.1590/S1413-82712004000100004

Maslach, C., \& Jackson, S. E. (1981). The measurement of experience burnout. Journal of Occupational Behavior, 2, 99-113. doi:10.1002/ job.4030020205

Maslach, C., Schaufeli, W. B., \& Leiter, M. P. (2001). Job burnout. Annual Review of Psychology, 52, 397-422. doi:10.1146/annurev.psych.52.1.397

Peres, A. M., \& Ciampone, M. H. T. (2006). Gerência e competências gerais do enfermeiro [Management and general skills of nurses]. Texto Contexto Enfermagem, 15(3), 492-499. doi:10.1590/ S0104-07072006000300015

Pisanti, R., van der Doef, M., Maes, S., Lazzari D., \& Bertini, M. (2011). Job characteristics, organizational conditions, and distress/well-being among Italian and Dutch nurses: A cross-national comparison. International Journal or Nursing Study, 48, 829-837. doi:10.1016/j.ijnurstu.2010.12.006

Phillips, J. (2011). Hardiness as a defense against compassion fatigue and burnout. Journal of Emergency Nursing, 37(2), 125. doi:10.1016/j. jen.2010.10.012

Pricewaterhouse Coopers. (2002). The factors fueling rising healthcare costs. Washington, DC: Author. 
Raiger, J. (2005). Applying a cultural lens to the concept of burnout. Journal of Transcultural Nursing, 16(1), 71-76. doi:10.1177/1043659604270980

Risquez, M. I. R., Fernández, C. G., \& Sánchez-Meca, J. (2011). Síndrome de quemarse por el trabajo, personalidad resistente y malestar psicológico en personal de enfermería [Burnout syndrome, Hardiness personality and psychological discomfort among nurses]. Anales de Psicología, 27(1), 71-79. doi:10.6018/analesps.27.1.113491

Saksvik-Lehouilliera, I., Bjorvatnbc, B., Hetlanda, H., Sandala, M. G., Moencd, E, B., Magerøyde, N., ...Pallesenab, S. (2012). Personality factors predicting changes in shift work tolerance: A longitudinal study among nurses working rotating shifts, Work \& Stress. An International Journal of Work, Health \& Organisations, 26(2), 143160. doi:10.1080/02678373.2012.686344

Schaufeli, W. B., \& Enzmann, D. (1998). The burnout companion to study and practice: A critical analysis. London: Taylor \& Francis.

Schaufeli, W. B., Leiter, M. P., \& Maslach, C. (2009). Burnout: 35 years of research and practice. $\mathrm{Ca}$ reer Development International, 14(3), 204-220. doi:10.1108/13620430910966406

Sheard, M., \& Golby, J. (2007). Hardiness and undergraduate academic study: The moderating role of commitment. Personality and Individual Differences, 43(3), 579-588. doi:10.1016/j. paid.2007.01.006

Silva, M. C. M., \& Gomes, A. R. (2009). Stress ocupacional em profissionais de saúde: Um estudo com médicos e enfermeiros portugueses [Occupational stress among health professionals: A study with Portuguese doctors and nurses]. Estudos de Psicologia (Natal), 14(3), 239-248. doi:10.1590/S1413-294X2009000300008
Simoni, S. P., \& Paterson, J. J. (1997). Hardiness, coping, and burnout in the nursing workplace. Journal of Professional Nursing, 13(3), 178185. doi:10.1016/S8755-7223(97)80069-5

Smith, P. B., Fischer, R., \& Sale, N. (2001). Cross-Cultural Industrial/Organizational Psychology. In C. L. Cooper \& I. T. Robertson (Eds.), International Review of Industrial and Organizational Psychology (Vol. 16, pp. 147-194). New York: John Wiley \& Sons.

Triandis, H., \& Suh, E. M. (2002). Cultural influences on personality. Annual Review of Psychology, 53(1), 133-160. doi:10.1146/annurev. psych.53.100901.135200

Turnipseed, D. L., \& Turnipseed, P. H. (1997). A bicultural analysis of the costs of caring: Nursing burnout in the United States and the Philippines. Career Development International, 2, 180-188. doi: $10.1108 / 13620439710173670$

Vanheule, S., Rosseel, Y., \& Vlerick, P. (2007). The factorial validity and measurement invariance of the Maslach Burnout Inventory for human services. Stress and Health, 23, 83-91. doi:10.1002/ smi. 1124

White, W. (2002). Nursing as vocation. Nursing Ethics, 9(3), 279-290. doi:10.1191/0969733002ne510oa

Recebido: 18/07/2013

Aceite final: 04/09/2013 